\title{
Effects of electron and ion irradiation on the annealing behavior of fission tracks and the microstructure of fluorapatite
}

\author{
W. X. Li*, K. Sun *, Q. M. Wei*, M. Lang***, L. M. Wang ****, R. C. Ewing***,*** \\ * Department of Material Sciences and Engineering, ** Department of Nuclear Engineering and \\ Radiological Sciences, *** Department of Geology, University of Michigan, Ann Arbor, MI 48109
}

Fission tracks in fluorapatite have been extensively used in mineral dating. Due to the shortening of spontaneous tracks over their life times up to tens of millions years, the geological thermal history can be interpreted by measuring etched track length. Numerous efforts have been made to quantify the kinetics of fission track annealing on the basis of laboratory experiments in which track length distributions are measured in crystals subjected to controlled thermal histories. However, the measured length of the etched tracks depends not only on original track length, but also on the mineral's response to the etchant. In this study, we report the results of in situ TEM studies of the annealing behavior of unetched Durango apatite fission tracks at temperature up to $700{ }^{\circ} \mathrm{C}$, with the emphasis on the effects of electron irradiation.

In situ thermal annealing experiments were performed using a JEOL 2010 TEM with a Gatan heating stage. Because fluorapatite is beam sensitive, only a low dose electron beam was used for recording images during the initial heating experiment. Fig. 1 shows that there are no obvious changes of the track after heating at $700^{\circ} \mathrm{C}$ for 10 hours. This result is significantly different with the optical microscopy observation of chemically etched apatite fission tracks where the tracks are completely annealed after heating at $360^{\circ} \mathrm{C}$ for 60 minutes [1]. As shown in Fig. 2, further electron beam irradiation at a higher dose rate at $700^{\circ} \mathrm{C}$ on the same grain caused track breakage and significant bubble formation. The bubbles formed gradually in apatite matrix, elongating along the [0001] direction with increasing dose. However, the breakage of the fission track (A) that is closer to the [0001] direction was significantly slower than that of the track (B) almost perpendicular to the [0001] direction. The [0001] direction favors the transport of fluorine atoms because of a large channel in the structure. Therefore, the tracks perpendicular to [0001] would be easier to break up, whereas the tracks or the bubbles parallel to [0001] would prefer an elongation rather than breaking up. This orientation effect on track annealing has also been observed by optical microscope in etched tracks [2]. Fig. 3 contains an HRTEM image of $2.2 \mathrm{GeV} \mathrm{Au}$ ion induced tracks and the thickness map of fission tracks that verified the hollow nature of the track core which was resulted by the escaping of fluorine gases decomposed under ionizing radiation.

The similarities of fission tracks and electron induced bubbles in the elongation along [0001] direction under radiolytic annealing at high temperature give a direct physical picture for understanding the crystallographic effect on fission track annealing.

References:

[1] K. D. Crowley et al., Geochimica et Cosmochimica Acta 55 (1991) 1449.

[2] R. A. Donelick et al., Am. Mineral. 76 (1991) 83.

[3] This work is supported by the U.S. Department of Energy under Grant Nos. DE-FG0799ID13767 and DEFG0202ER46005. 


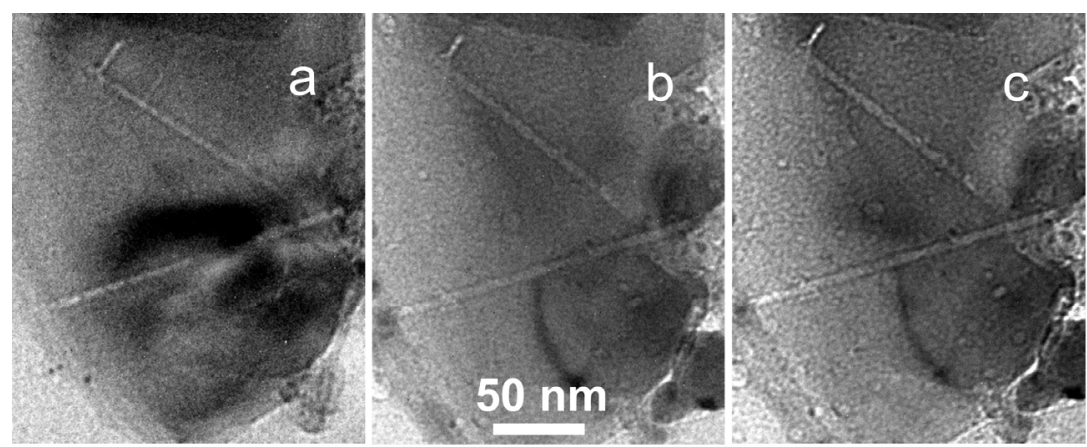

FIG.1. TEM images of fission tracks in apatite during thermal annealing. (a) before heating, (b) during heating at $700^{\circ} \mathrm{C}$ and (c) after heating at $700^{\circ} \mathrm{C}$ for 600 minutes.

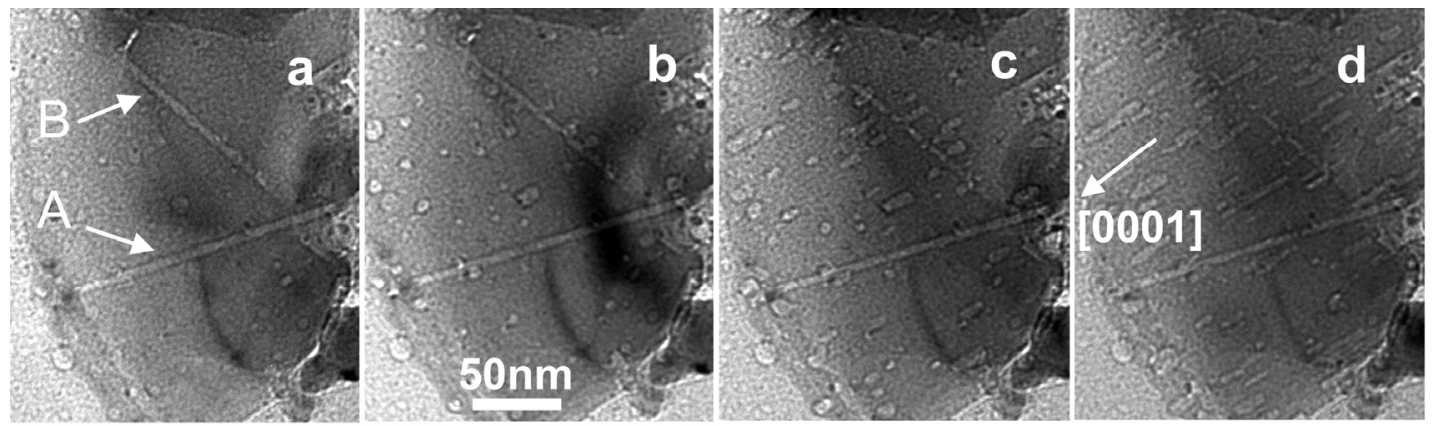

FIG.2. Further continuous exposure to the electron beam leads the fission tracks to fade rapidly at a dose of (a) 0 , (b) $3.6 \times 10^{19}$, (c) $2.9 \times 10^{20}$ and (d) $1.2 \times 10^{21} \mathrm{e}^{-} / \mathrm{cm}^{2}$. Electron beam exposure also induces bubbles forming and elongating along [0001] direction.
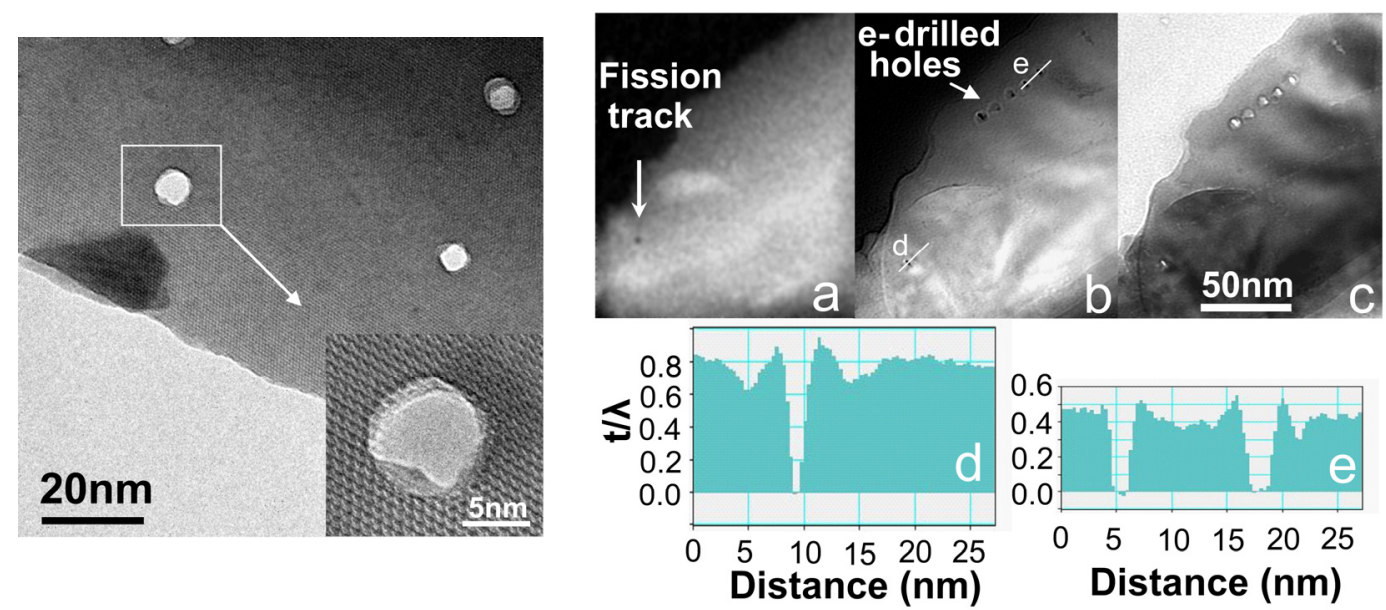

FIG.3. TEM micrographs and corresponding thickness maps showing the hollow nature of irradiation induced tracks in fluorapatite. The images on the left are from a $2.2 \mathrm{GeV}$ Au irradiated sample. The images on the right are from a sample that contains fission tracks and electron beam drilled holes: (a) Dark field image before drilling holes; (b) Thickness map after drilling holes; (c) Energy filtered elastic image after drilling holes; (d) Thickness profile along Line d through the fission track as highlighted in the bottom left of (b); (e) Thickness profile along Line e cutting two electron-beam-drilled holes as highlighted in the upper right of image (b). 